\title{
Alasdair Drysdale
}

\section{POPULATION DYNAMICS AND BIRTH SPACING IN OMAN}

At the time of its first modern census in 1993, Oman had one of the world's highest fertility rates (6.9 children per woman) and over half of the population was under the age of fifteen and yet to enter its peak childbearing years. In response, Oman introduced a Birth Spacing Program in 1994, encouraging couples to space births by at least three years and making a wide range of modern contraceptives available throughout the sultanate. Although the program was ostensibly designed to promote reproductive and child health, it clearly had a demographic agenda. By 2006, the fertility rate had dropped to 3.2 children per woman and the contraceptive prevalence rate had increased sharply. However, these changes cannot be attributed solely to the Birth Spacing Program and must be seen in the broader context of delayed marriage and extraordinary gains in social well-being, health, and female education. 